\title{
Diagnostic performance of the calcium/ phosphate ratio for primary hyperparathyroidism in southwest China
}

\author{
Mengting Yin ${ }^{1}$, Qianhui Liu' ${ }^{1}$ Qingzhong Wang${ }^{2}$, Yong He${ }^{1}$, Haolan Song ${ }^{1}$, Xin $\mathrm{Nie}^{1}$ and Guixing $\mathrm{Li}^{1}$ \\ ${ }^{1}$ Sichuan University West China Hospital, Chengdu, China \\ 2Jintang First People's Hospital, West China Hospital Sichuan University Jingtang Hospital, Chengdu, China
}

Correspondence should be addressed to G Li: liguixing27@163.com

\begin{abstract}
Background: The diagnosis of primary hyperparathyroidism (PHPT) remains a challenge because of increased asymptomatic PHPT or patients with normocalcaemic PHPT (NPHPT). In addition, some primary hospitals in China have no equipment to measure parathyroid hormone (PTH) levels. Therefore, an additional, simple, and inexpensive laboratory biochemical marker is urgently needed. The calcium/phosphate (Ca/P) ratio and chloride/ phosphate (CI/P) ratio have been proposed as suitable tools to diagnose PHPT in Europe; however, the $\mathrm{Ca} / \mathrm{P}$ ratio has never been tested in China. We aimed to conduct a confirmatory study to explore the diagnostic performance of the Ca/P ratio for PHPT in China. Methods: From January 2015 to December 2020, a total of 155 patients who underwent parathyroidectomy (143 PHPT patients and 12 NPHPT patients) and 153 controls were enrolled in this single-center, retrospective study. Serum calcium, phosphate, parathyroid hormone, 25-hydroxyvitamin vitamin $\mathrm{D}(25(\mathrm{OH})$ vitamin $\mathrm{D})$, chloride, alanine transaminase (ALT), aspartate aminotransaminase (AST), estimated glomerular filtration rate (eGFR), and creatinine levels were recorded for all the study participants. Pairwise comparisons were made between groups, and the diagnostic performance of the $\mathrm{Ca} / \mathrm{P}$ ratio was determined using receiver-operating characteristic (ROC) analysis.

Results: Patients with PHPT had a higher $\mathrm{Ca} / \mathrm{P}$ ratio than controls $(P<0.001)$. A Ca/P ratio above 2.94 with a sensitivity of $95.5 \%$ and specificity of $98.7 \%$ can distinguish PHPT patients from healthy individuals. This index was positively correlated with the PTH level $(r=0.875, P<0.001)$.

Conclusion: The $\mathrm{Ca} / \mathrm{P}$ ratio is an ideal and inexpensive indicator for diagnosing PHPT in China when using a cut-off value of 2.94 .
\end{abstract}

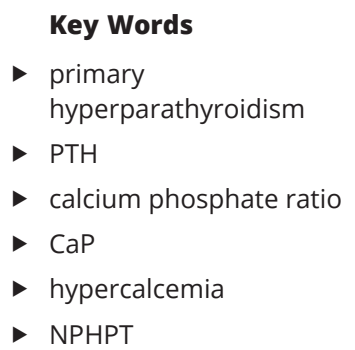

\section{Introduction}

Primary hyperparathyroidism (PHPT) is a common endocrine disease caused by parathyroid dysfunction, with a prevalence of approximately $1 / 1000-7 / 1000$ in the general population (1). Approximately $80 \%$ of PHPT cases are caused by a single parathyroid adenoma and less than $1 \%$ by parathyroid adenocarcinoma (2). Traditionally, patients with PHPT typically have hypercalcemia and elevated parathyroid hormone (PTH) levels $(3,4)$. Dysregulation of $\mathrm{PTH}$, the most important metabolic hormone required for the maintenance of the homeostasis of calcium and phosphate, can lead to skeletal, renal, and cardiovascular complications, including hypercalcemia, hypophosphatemia, osteoporosis, fragility fractures, bone pain, nephrolithiasis, ventricular hypertrophy, and

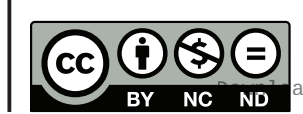

This work is licensed under a Creative Commons Attribution-NonCommercial-NoDerivatives 4.0 enternationad ticense ifica.com at 04/26/2023 01:58:45PM 
myocardial calcification $(5,6)$. Parathyroidectomy (PTX) is the only beneficial treatment modality for all individuals with symptomatic PHPT and asymptomatic patients who meet any of the guideline criteria for surgical intervention (6). At present, the mainstay of the diagnosis of PHPT is the clinical manifestations and routine serum calcium and PTH detection $(6,7,8)$. However, the prevalence of asymptomatic PHPT increased by approximately 50\% in China between 2007 and 2010 (9), and cases of normocalcaemic PHPT (NPHPT) characterized by inappropriately elevated PTH levels in the setting of normal serum calcium after the exclusion of secondary hyperparathyroidism, including vitamin D deficiency and chronic kidney disease have already been confirmed. The hypotheses regarding the pathogenesis of NPHPT are as follows: (1) the normocalcaemic phenotype may represent an early or mild stage of traditional PHPT $(10,11)$; and (2) renal tubular resistance to PTH (12). Some primary hospitals in China have no equipment capable of measuring the PTH levels. All of these have brought about a challenge in the diagnosis of PHPT. Therefore, we need to look for an additional, simple, and inexpensive laboratory biochemical marker to diagnose PHPT. Considering the pathogenesis of the condition, there have been studies focused on the utility of the calcium/phosphate ratio $(\mathrm{Ca} / \mathrm{P})$ and the chloride/phosphate ratio $(\mathrm{Cl} / \mathrm{P})$. Madeo et al . reported that a cut-off of 2.71 for the $\mathrm{Ca} / \mathrm{P}$ ratio has a better predictive value than serum calcium or PTH levels for PHPT, especially in NPHPT, with a sensitivity and specificity of 86 and $87 \%$, respectively (13). Wright et al. also reported an AUC of 0.813 for the $\mathrm{Ca} / \mathrm{P}$ ratio with a sensitivity of $95.6 \%$ and specificity of $63.6 \%$, when using a cut-off value of 2.55 (14). Reeve et al. revealed that a $\mathrm{Cl} / \mathrm{P}$ ratio of $>33$ can be used for PHPT with a sensitivity of $94 \%$ and specificity of $96 \%$ (15). Recently, a study confirmed that a $\mathrm{Cl} / \mathrm{P}$ ratio of $>33$ for NPHPT had a sensitivity of $73.7 \%$ and a specificity of $80.0 \%$ in the Chinese population (16). Meanwhile, a comparison between $\mathrm{Ca} / \mathrm{P}$ and $\mathrm{Cl} / \mathrm{P}$ suggested that $\mathrm{Ca} / \mathrm{P}$ was more sensitive than $\mathrm{Cl} / \mathrm{P}$ (14). Therefore, given that no study has tested the $\mathrm{Ca} / \mathrm{P}$ ratio in Europe since previous studies were all focused on European cohorts, we aimed to conduct a confirmatory study to explore the diagnostic performance of the $\mathrm{Ca} / \mathrm{P}$ ratio in China and make a comparison between the diagnostic accuracies of the $\mathrm{Ca} / \mathrm{P}$ and $\mathrm{Cl} / \mathrm{P}$ ratios.

\section{Methods}

\section{Study participants}

This was a single-center, retrospective, case-control study. Data were obtained from electronic medical records at the
West China Hospital. We enrolled a total of 308 patients, of whom 12 had NPHPT, 143 had PHPT, and 153 were healthy. Patients with NPHPT were defined by serum PTH $>6.9$ $\mathrm{pmol} / \mathrm{L}$ (or in the upper range of normal values) but serum calcium levels within the reference range (2.11-2.52 $\mathrm{mmol} / \mathrm{L}$ ) within the 1 year prior to PTX after the exclusion of secondary hyperparathyroidism, including vitamin D deficiency or chronic kidney disease. Patients with NPHPT received vitamin D supplementation for at least 8 weeks to ensure the correctness of the diagnosis. Patients with PHPT were defined as having serum PTH $>6.9 \mathrm{pmol} / \mathrm{L}$ and serum calcium $>2.52 \mathrm{mmol} / \mathrm{L}$. Only patients treated with PTX and confirmed by histopathology were recruited. Plasma albumin-adjusted corrected calcium levels were calculated as follows: corrected calcium $(\mathrm{mmol} / \mathrm{L})=$ measured calcium $(\mathrm{mmol} / \mathrm{L})+0.02 \times(40$-patient's serum albumin concentration $(\mathrm{g} / \mathrm{L}))(17)$. Healthy controls should have a normal PTH concentration (reference range: 1.6-6.9 $\mathrm{pmol} / \mathrm{L}$ ). All experimental protocols involving human data were approved by the Medical Ethics Committee of the Sichuan University, which waived the requirement for informed consent. We also ensured that all methods were performed in accordance with the relevant regulations. The selection criteria are shown in Fig. 1.

\section{Study variables}

Data on the following parameters were collected in the different groups: age, sex, serum calcium, phosphate, PTH, 25-hydroxyvitamin D $(25(\mathrm{OH})$ vitamin D), chloride, alanine transaminase (ALT), aspartate aminotransaminase (AST), estimated glomerular filtration rate (eGFR), and creatinine. The inclusion criteria for the experimental group were as follows: (1) a diagnosis of PHPT or NPHPT as detailed above; (2) history of parathyroidectomy; (3) histopathological confirmation; and (4) normalization of postoperative calcium. The exclusion criteria were as follows: (1) intake of medications such as hydrochlorothiazide, diuretics, lithium, bisphosphonates, and denosumab; (2) renal insufficiency $\left(e G F R<30 \mathrm{~mL} / \mathrm{min} / 1.73 \mathrm{~m}^{2}\right)$ and abnormal liver function (ALT or AST greater than twice the normal value); and (3) missing data. We chose healthy controls from the Physical Examination Center of the West China Hospital. People with normal biochemical levels and thyroid ultrasound were included in the same time period.

\section{Statistical analysis}

Measurement data on normal distribution were expressed as mean \pm S.D.. Abnormal distribution data are

This work is licensed under a Creative Commons Attribution-NonCommercial-NoDerivatives 4.0 International License if ica, com at $04 / 26 / 2023$ 01:58:45PM 


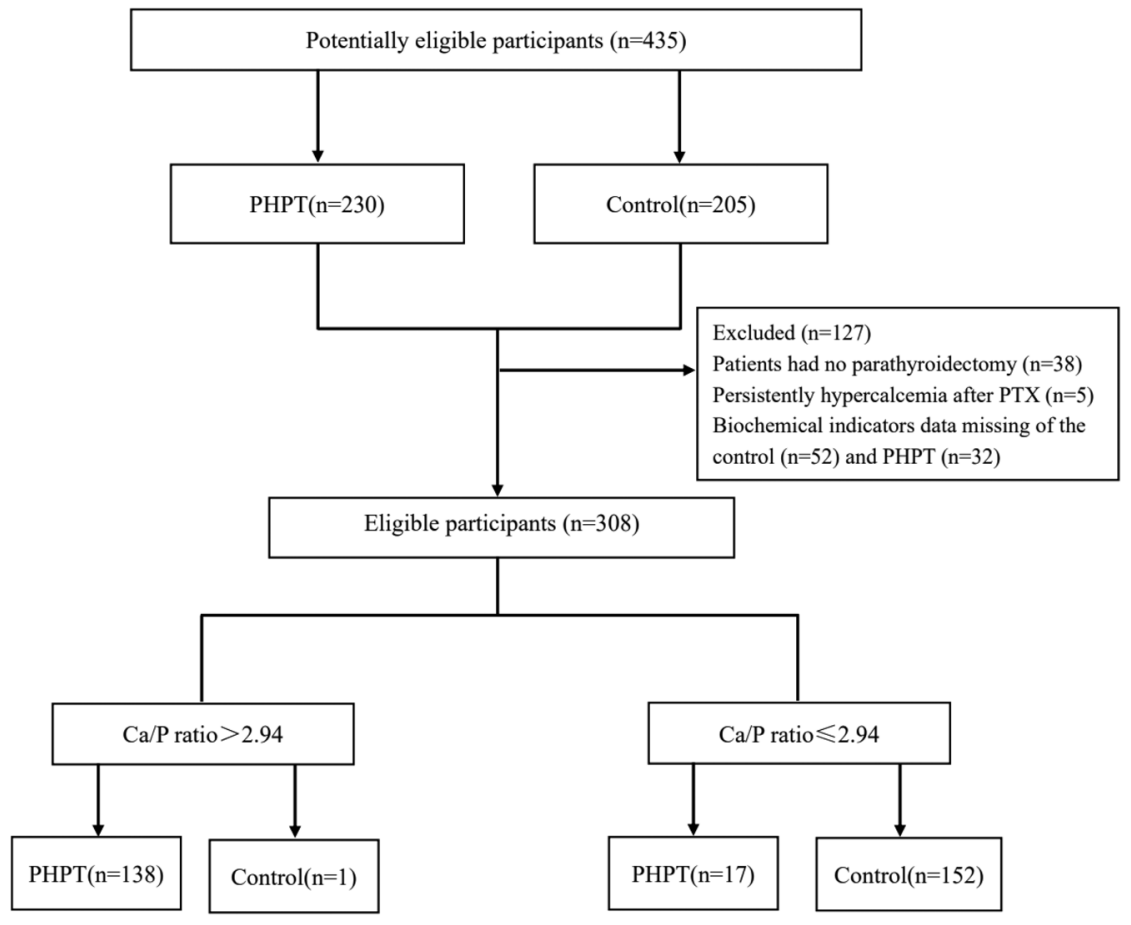

Figure 1

The process of the selection criteria. expressed as median (interquartile range (IQR)). Except for age, all continuous data were skewed and tested using the Mann-Whitney U test. The analyses were completed using SPSS software (version 25.0). We also calculated the $\mathrm{Ca} / \mathrm{P}$ ratio of calcium $(\mathrm{mmol} / \mathrm{L}) / \mathrm{phosphate}(\mathrm{mmol} / \mathrm{L})$ and $\mathrm{Cl} / \mathrm{P}$ ratio chloride $(\mathrm{mEq} / \mathrm{L}) / \mathrm{phosphate}(\mathrm{mg} / 100 \mathrm{~mL})$. The evaluation of diagnostic performance is typically based on the receiver-operating characteristic (ROC) curve and the area under the curve (AUC) with 95\% CIs. The Spearman correlation coefficient was used in the case of skewed data, while the Pearson correlation coefficient was made in the case of normally distributed data. The sensitivity, specificity, positive and negative predictive values, and their 95\% CIs were calculated using MedCalc Software 19 (Mariakerke, Belgium). All $P$-values were two-tailed, and statistical significance was set at $P<0.05$.

\section{Results}

\section{Characteristics of the study cohorts}

The clinical characteristics of the cohort are presented in Table 1. Patients with PHPT had higher values of PTH, serum calcium, $\mathrm{Ca} / \mathrm{P}$ ratio, and $\mathrm{Cl} / \mathrm{P}$ ratio, but lower serum levels of $25(\mathrm{OH})$ vitamin $\mathrm{D}$ and phosphate than healthy controls $(P<0.001)$. Age, sex, creatinine, and albumin levels did not differ significantly between the two groups $(P>0.05)$.

\section{The diagnostic power for the $\mathrm{Ca} / \mathrm{P}$ ratio}

We analyzed the diagnostic performance of the $\mathrm{Ca} / \mathrm{P}$ ratio using ROCs. The cut-off point was calculated using Youden's index (sensitivity+specificity - 1). The ROC curve showed that the ROC-AUC was 0.993 (95\% CI, 0.976-0.998), sensitivity, and specificity rates of $95.5 \%$ (95\% CI, 90.0-98.2) and $98.7 \%$ (95\% CI, 95.4-99.8), respectively, at a Ca/P ratio of $>2.94$ (Fig. 2A). The logistic regression model was as follows: $\operatorname{logit}(\mathrm{P})=-23.847+8.342 \times \mathrm{Ca} / \mathrm{P}$.

\section{The diagnostic power for the $\mathrm{Cl} / \mathrm{P}$ ratio}

We analyzed the diagnostic performance of the $\mathrm{Cl} / \mathrm{P}$ ratio through ROCs. The cut-off point was calculated using Youden's index (sensitivity+specificity -1 ). The ROC curve showed that the ROC-AUC was 0.966 (95\% CI, 0.940-0.983), sensitivity, and specificity rates of 95.5 (95\% CI, 90.9-98.2) and 91.5 (95\% CI, 85.9-95.4), respectively, at a $\mathrm{Cl} / \mathrm{P}$ ratio of 32.4 (Fig. 2B).

\section{Correlation between $\mathrm{Ca} / \mathrm{P}$ ratio and other parameters}

We performed a Spearman correlation analysis between the $\mathrm{Ca} / \mathrm{P}$ ratio and the $\mathrm{Cl} / \mathrm{P}$ ratio, $\mathrm{PTH}$, and $25(\mathrm{OH})$ vitamin D3. The $\mathrm{Ca} / \mathrm{P}$ ratio was positively correlated with the $\mathrm{Cl} / \mathrm{P}$ ratio $(r=0.882, P<0.001)$ and PTH $(r=0.875, P<0.001)$ and negatively correlated with $25(\mathrm{OH})$ vitamin D3 $(r=-0.260$, $P<0.001)$.

is work is licensed under a Creative Commons Attribution-NonCommercial-NoDerivatives 4.0 elnternationad dicense ifica. com at 04/26/2023 01:58:45PM 
Table 1 Characteristic of subjects in control and PHPT groups.

\begin{tabular}{l}
\hline \\
\hline Age (years) \\
Gender $(n(\%))$ \\
$\quad$ Female \\
$\quad$ Male \\
ALT (U/L) \\
AST (U/L) \\
Creatinine (41-73 mmol/L) \\
eGFR (mL/min) \\
Albumin (g/L) \\
PTH (1.6-6.9 pmol/L) \\
25(OH) vitamin D (47.7-144)nmol/L \\
Serum calcium $(2.11-2.52 \mathrm{mmol} / \mathrm{L})$ \\
Serum phosphate $(0.85-1.51 \mathrm{mmol} / \mathrm{L})$ \\
Chloride (mmol/L) \\
Ca/P \\
Cl/P
\end{tabular}

\begin{tabular}{c}
\hline PHPT \\
\hline $48 \pm 15$ \\
$51(32.9)$ \\
$104(67.1)$ \\
$18(14,25)$ \\
$20(17,23)$ \\
$63(60-73)$ \\
$100.4(82.5,115.0)$ \\
$45.0(43.0-47.3)$ \\
$21.1(13.7-37.0)$ * \\
$36.5(26.4-46.3)^{*}$ \\
$2.75(2.58-2.95)^{*}$ \\
$0.75(0.65-0.82)$ * \\
$105.7(103.3,108.3)^{*}$ \\
$3.71(3.27-4.62)$ * \\
$39.6(25.3-89.6)$ * \\
\hline
\end{tabular}

\begin{tabular}{ccc}
\hline Healthy & & P value \\
$64 \pm 13$ & & 0.65 \\
$61(39.9)$ & & 0.61 \\
$92(60.1)$ & & \\
$19(14,26)$ & & 0.23 \\
$21(17,27)$ & & 0.04 \\
$68(60-84)$ & & 0.49 \\
$120.0(110.9,141.0)$ & & 0.001 \\
$45.2(44.0-46.8)$ & & 0.54 \\
$4.9(4.1-5.5)$ & & $<0.001$ \\
$58.1(47.3-75.3)$ & & $<0.001$ \\
$2.36(2.30-2.41)$ & & $<0.001$ \\
$1.01(0.90-1.12)$ & & $<0.001$ \\
$101.4(99.8,103.0)$ & & $<0.001$ \\
$2.35(2.10-2.61)$ & $<0.001$ \\
$26.3(18.2-45.5)$ & $<0.001$ \\
\hline
\end{tabular}

eGFR was calculated by using the following modification of diet in renal disease $\left(\right.$ MDRD) formula: eGFR $=186 \times(\text { serum creatinine })^{-1.154} \times(\text { age })^{-0.203} \times$ $(1.20$ if black $) \times(0.742$ if female $)$.

$* P<0.001$.

ALT, alanine transaminase; AST, aspartate aminotransferase; $\mathrm{Ca} / \mathrm{P}$, calcium/phosphate ratio; Cl/P, chloride/phosphate ratio; eGFR, estimated glomerular filtration rate; PHPT, primary hyperparathyroidism; PTH, parathyroid hormone.

\section{Discussion}

Traditionally, the diagnosis of PHPT relies mainly on clinical manifestations and the routine detection of serum calcium and PTH levels. However, many patients with PHPT are asymptomatic $(18,19,20)$. It has been reported that asymptomatic patients account for the vast majority of PHPT cases in the USA and Western Europe, and asymptomatic PHPT has become the most common presentation (21). In China, the proportion of asymptomatic cases also increased to approximately 50\% between 2007 and $2010(9,18)$. We can infer that the clinical pattern of PHPT has now entered an era of a more asymptomatic type. Recently, some researchers
A

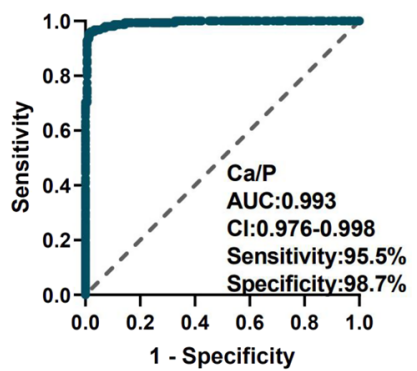

B

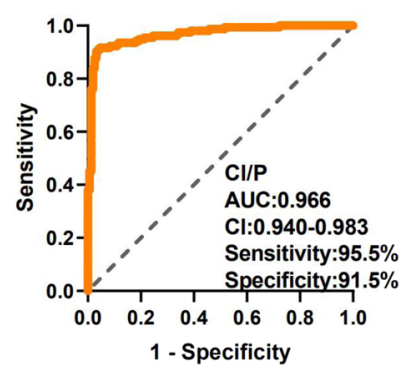

Figure 2

Receiver-operating characteristic curves (ROCs) used for PHPT of $\mathrm{Ca} / \mathrm{P}$ ratio and CI/P ratio. (A) ROC curve analysis for $\mathrm{Ca} / \mathrm{P}$ ratio together with AUC, 95\% Cl values, sensitivity, and specificity. (B) ROC curve analysis for $\mathrm{Ca} / \mathrm{P}$ ratio together with $\mathrm{AUC}, 95 \% \mathrm{CI}$ values, sensitivity, and specificity. have focused on the utility of the $\mathrm{Cl} / \mathrm{P}$ or $\mathrm{Ca} / \mathrm{P}$ ratio, and they found that PHPT could be excluded when the $\mathrm{Cl} / \mathrm{P}$ ratio was $<33$ or $\mathrm{Ca} / \mathrm{P}$ ratio $>2.55$ with a good predictive value $(13,14,16,22)$. We also measured this model in the present study. The ROC-AUC of the $\mathrm{Cl} / \mathrm{P}$ ratio was 0.966 (95\% CI, 0.940-0.983), sensitivity and specificity rates of $95.5 \%$ (95\% CI, 90.9-98.2) and 91.5\% (95\% CI, 85.9-95.4), respectively, at a $\mathrm{Cl} / \mathrm{P}$ ratio of 32.4 , which was similar to theirs. The ROC-AUC of the $\mathrm{Ca} / \mathrm{P}$ ratio was 0.993 (95\% CI, 0.976-0.998), and the sensitivity and specificity rates were 95.5\% (95\% CI, 90.0-98.2) and $98.7 \%$ (95\% CI, 95.4-99.8), respectively. A possible explanation is that high levels of PTH in patients with PHPT can inhibit phosphate reabsorption from proximal renal tubules but increase chloride reabsorption from these same tubules. Wright et al. compared the $\mathrm{Ca} / \mathrm{P}$ ratio with $\mathrm{Cl} / \mathrm{P}$ and found that the $\mathrm{AUC}$ for the $\mathrm{Cl} / \mathrm{P}$ ratio was 0.712 , which was inferior to the $\mathrm{Ca} / \mathrm{P}$ ratio $(A U C=0.813)(14)$. In our study, we also found that the $\mathrm{Ca} / \mathrm{P}$ ratio had a better predictive value than the $\mathrm{Cl} / \mathrm{P}$ ratio in the diagnosis of PHPT (0.993 (95\% CI, 0.9760.998 ) vs 0.966 (95\% CI, $0.940-0.983), P=0.005$ ). In this study, the ratio at a threshold of 2.94 can correctly identify 9 out of 12 NPHPT patients, 138 out of the 143 PHPT patients and only 1 out of the 153 controls were incorrectly diagnosed with PHPT. The mechanism is as follows: (1) PTH directly increases calcium absorption and decreases phosphate reabsorption in the proximal tubule of the kidney; (2) PTH promotes the conversion

This work is licensed under a Creative Commons Attribution-NonCommercial-NoDerivatives 4.0 enternationab dicense.ifica . com at 04/26/2023 01:58:45PM 
of $25(\mathrm{OH})$ vitamin $\mathrm{D}$ to 1,25 -dihydroxyvitamin $\mathrm{D}$ by increasing the activity of $1 \alpha$-hydroxylase in the proximal tubule of the kidney, which promotes gut calcium and phosphate absorption. Although other studies have already investigated the $\mathrm{Ca} / \mathrm{P}$ ratio in the diagnosis of PHPT, they did not compare the $\mathrm{Ca} / \mathrm{P}$ ratio with the $\mathrm{Cl} / \mathrm{P}$ ratio $(13,23,24,25)$. In another study by Madeo et al., the cut-off $\mathrm{Ca} / \mathrm{P}$ value of 2.55 was able to correctly identify 101 out of 142 NPHPT patients, showing a high sensitivity (71.1\%) and specificity (87.9\%), which is in line with our findings (13). When using a cut-off of 2.55 in our study, the sensitivity and specificity were 99.4 and $83.1 \%$, respectively. When using a cut-off of 2.55 in our study, the sensitivity and specificity were 99.4 and $83.1 \%$, respectively. We guess that the reason data available in the literature suggested a different cut-off for $\mathrm{Ca} / \mathrm{P}$ in the diagnosis of PHPT was because of: (1) study cohorts; (2) measuring methods and equipment; and (3) the different proportion of the NPHPT in experimental group. Our results indicated that the $\mathrm{Ca} / \mathrm{P}$ ratio is an ideal and inexpensive indicator that can be used to diagnose PHPT and has a good correlation with the serum PTH level $(r=0.875, P<0.001)$, which successfully solved the problem of some primary hospitals in remote areas in China not having the required equipment to determine the serum levels of PTH. In summary, the results of this study demonstrate that the $\mathrm{Ca} / \mathrm{P}$ ratio is an inexpensive and convenient indicator for diagnosing PHPT. Although this index cannot replace the gold standard of imaging, the utility of this ratio may alert clinicians to the possibility of PHPT when patients are asymptomatic Moreover, this ratio is useful for laboratories and clinics with limited resources in lowincome geographical areas. There are some limitations to this study. The majority of patients with PHPT were postmenopausal women, however, we did not match age and sex in the selection of the control group. Second, we only included patients with parathyroid adenoma but not those with parathyroid carcinoma, and we excluded patients who did not undergo parathyroidectomy. Although the inclusion of PHPT was defined by serum calcium $>2.52 \mathrm{mmol} / \mathrm{L}$ together with $\mathrm{PHT}>6.9 \mathrm{pmmol} / \mathrm{L}$ or in the upper range of the normal values, there were no PHPT patients with normal PTH levels in this study. We will focus on this type of PHPT and verify the diagnostic performance of the $\mathrm{Ca} / \mathrm{P}$ ratio in further research. Meanwhile, no data are available at the moment as far as ethnic differences of the diagnostic performance of $\mathrm{Ca} / \mathrm{P}$ ratio are concerned, so the results should be confined to the Chinese population.

\section{Conclusion}

The $\mathrm{Ca} / \mathrm{P}$ ratio is an ideal indicator for screening PHPT. PHPT can be identified in healthy individuals when the $\mathrm{Ca} / \mathrm{P}$ ratio is above 2.94 in the Chinese population.

\section{Declaration of interest}

All authors have read the journal's authorship agreement and policy. They declare that there is no conflict of interest regarding the publication of this paper.

\section{Funding}

This work did not receive any specific grant from any funding agency in the public, commercial, or not-for-profit sector.

\section{Ethics approval and consent to participate}

All the experiment protocol for involving human data was approved by the Medical Ethics Committee of Sichuan University. And this study was also approved to waive the requirement for informed consent by the Medical Ethics Committee of Sichuan university.

\section{References}

1 Yeh MW, Ituarte PH, Zhou HC, Nishimoto S, Liu IL, Harari A, Haigh PI \& Adams AL. Incidence and prevalence of primary hyperparathyroidism in a racially mixed population. Journal of Clinical Endocrinology and Metabolism 201398 1122-1129. (https://doi. org/10.1210/jc.2012-4022)

2 Insogna KL. Primary hyperparathyroidism. New England Journal of Medicine 2018379 1050-1059. (https://doi.org/10.1056/ NEJMcp1714213)

3 Syed H \& Khan A. Primary hyperparathyroidism: diagnosis and management in 2017. Polish Archives of Internal Medicine 2017127 438-441. (https://doi.org/10.20452/pamw.4029)

4 Turner JJO. Hypercalcaemia - presentation and management. Clinical Medicine 201717 270-273. (https://doi.org/10.7861/ clinmedicine.17-3-270)

5 Silva BC, Cusano NE \& Bilezikian JP. Primary hyperparathyroidism. Best Practice and Research: Clinical Endocrinology and Metabolism 2018 32 593-607. (https://doi.org/10.1016/j.beem.2018.09.004)

6 Khan AA, Hanley DA, Rizzoli R, Bollerslev J, Yong JE, Rejnmark L, Thakker R, D'Amour P, Paul T, Van Uum S, et al. Primary hyperparathyroidism: review and recommendations on evaluation, diagnosis, and management. A Canadian and International Consensus. Osteoporosis International 201728 1-19. (https://doi. org/10.1007/s00198-016-3716-2)

7 Roeher HD \& Schmidt-Gayk H. Diagnosis of primary and secondary hyperparathyroidism. World Journal of Surgery 19771 709-720. (https://doi.org/10.1007/BF01555921)

8 Nordenstrom E, Katzman P \& Bergenfelz A. Biochemical diagnosis of primary hyperparathyroidism: analysis of the sensitivity of total and ionized calcium in combination with PTH. Clinical Biochemistry 2011 44 849-852. (https://doi.org/10.1016/j.clinbiochem.2011.04.002)

9 Silverberg SJ, Clarke BL, Peacock M, Bandeira F, Boutroy S, Cusano NE, Dempster D, Lewiecki EM, Liu JM, Minisola S, et al. Current issues in the presentation of asymptomatic primary hyperparathyroidism: proceedings of the Fourth International Workshop. Journal of Clinical Endocrinology and Metabolism 201499 3580-3594. (https://doi. org/10.1210/jc.2014-1415) 
10 Lowe H, McMahon DJ, Rubin MR, Bilezikian JP \& Silverberg SJ. Normocalcemic primary hyperparathyroidism: further characterization of a new clinical phenotype. Journal of Clinical Endocrinology and Metabolism 200792 3001-3005. (https://doi. org/10.1210/jc.2006-2802)

11 Cusano NE, Cipriani C \& Bilezikian JP. Management of normocalcemic primary hyperparathyroidism. Best Practice and Research: Clinical Endocrinology and Metabolism 201832 837-845. (https://doi.org/10.1016/j.beem.2018.09.009)

12 Maruani G, Hertig A, Paillard M \& Houillier P. Normocalcemic primary hyperparathyroidism: evidence for a generalized target-tissue resistance to parathyroid hormone. Journal of Clinical Endocrinology and Metabolism 200388 4641-4648. (https://doi.org/10.1210/ jc.2002-021404)

13 Madeo B, Kara E, Cioni K, Vezzani S, Trenti T, Santi D, Simoni M $\&$ Rochira V. Serum calcium to phosphorous $(\mathrm{Ca} / \mathrm{P})$ ratio is a simple, inexpensive, and accurate tool in the diagnosis of primary hyperparathyroidism. JBMR Plus 20182 109-117. (https://doi. org/10.1002/jbm4.10019)

14 Wright C, King D, Small M, Gibson C, Gardner R \& Stack Jr BC. The utility of the $\mathrm{Cl}: \mathrm{PO} 4$ ratio in patients with variant versions of primary hyperparathyroidism. Otolaryngology: Head and Neck Surgery 2021164 308-314. (https://doi.org/10.1177/0194599820947009)

15 Broulík PD \& Pacovský V. The chloride phosphate ratio as the screening test for primary hyperparathyroidism. Hormone and Metabolic Research 197911 577-579. (https://doi. org/10.1055/s-0028-1092784)

16 Wang Q, Li X, Chen H, Yu H, Li L, Yin J, Zhou J, Li M, Li Q, Han J, et al. The chloride/phosphate ratio combined with alkaline phosphatase as a valuable predictive marker for primary hyperparathyroidism in Chinese individuals. Scientific Reports 20177 4868. (https://doi. org/10.1038/s41598-017-05183-6)

17 Marcocci C \& Cetani F. Clinical practice. Primary hyperparathyroidism. New England Journal of Medicine 2011365 2389-2397. (https://doi.org/10.1056/NEJMcp1106636)
18 Zhao L, Liu JM, He XY, Zhao HY, Sun LH, Tao B, Zhang MJ, Chen X, Wang WQ \& Ning G. The changing clinical patterns of primary hyperparathyroidism in Chinese patients: data from 2000 to 2010 in a single clinical center. Journal of Clinical Endocrinology and Metabolism 201398 721-728. (https://doi.org/10.1210/jc.2012-2914)

19 Clarke BL. Asymptomatic primary hyperparathyroidism. Frontiers of Hormone Research 201951 13-22. (https://doi. org/10.1159/000491035)

20 Bilezikian JP, Brandi ML, Eastell R, Silverberg SJ, Udelsman R, Marcocci C \& Potts JT. Guidelines for the management of asymptomatic primary hyperparathyroidism: summary statement from the Fourth International Workshop. Journal of Clinical Endocrinology and Metabolism 201499 3561-3569. (https://doi. org/10.1210/jc.2014-1413)

21 Walker MD \& Silverberg SJ. Primary hyperparathyroidism. Nature Reviews: Endocrinology 201814 115-125. (https://doi.org/10.1038/ nrendo.2017.104)

22 Boughey JC, Ewart CJ, Yost MJ, Nottingham JM \& Brown JJ. Chloride/ phosphate ratio in primary hyperparathyroidism. American Surgeon $20047025-28$.

23 Madeo B, De Vincentis S, Repaci A, Altieri P, Vicennati V, Kara E, Vescini F, Amadori P, Balestrieri A, Pagotto U, et al. The calciumto-phosphorous $(\mathrm{Ca} / \mathrm{P})$ ratio in the diagnosis of primary hyperparathyroidism and hypoparathyroidism: a multicentric study. Endocrine 202068 679-687. (https://doi.org/10.1007/s12020020-02276-7)

24 Madeo B, De Vincentis S, Kara E, Vescini F, Trenti T, Guaraldi G \& Rochira V. Reliability of calcium-phosphorus $(\mathrm{Ca} / \mathrm{P})$ ratio as a new, accurate and inexpensive tool in the diagnosis of some Ca-P disorders. Journal of Endocrinological Investigation 201942 1041-1049. (https:// doi.org/10.1007/s40618-019-01025-6)

25 Guo Y, Wang Q, Lu C, Fan P, Li J, Luo X \& Chen D. New parathyroid function index for the differentiation of primary and secondary hyperparathyroidism: a case-control study. BMC Endocrine Disorders 202020 5. (https://doi.org/10.1186/s12902-019-0487-8)

Received in final form 22 August 2021

Accepted 24 September 2021

Accepted Manuscript published online 24 September 2021 https://ec.bioscientifica.com https://doi.org/10.1530/EC-21-0267 (c) 2021 The authors Published by Bioscientifica Ltd
This work is licensed under a Creative Commons Attribution-NonCommercial-NoDerivatives 4.0 elfternationad ficense ifica . com at 04/26/2023 01:58:45PM 